\title{
CARTAS PARA O FÛHRER: A POPULARIDADE DO PARTIDO NAZISTA ANALISADO PELAS SUAS CORRESPONDÊNCIAS
}

\author{
Pedro Chaves Lima1 \\ Jéssica Oliveira dos Santos ${ }^{2}$ \\ Felipe Matheus Pereira ${ }^{3}$ \\ Valéria Regina Zanetti ${ }^{4}$
}

Resumo: O artigo tem como objetivo medir o índice de popularidade de Hitler e do Partido NacionalSocialista (Partido Nazista) a partir das correspondências encaminhadas ao Füher nos anos de 1933-1938, reunidas no livro Cartas para Hitler, de Henrik Eberle. As cartas, que expressam os sentimentos, ideias, posições e os mais diversos desejos de cidadãos comuns aos mais altos condecorados militares alemães, foram analisadas a partir da perspectiva quanti-qualitativa, como forma de conhecer os motivos das queixas e elogios dos alemães ao nazismo. As cartas foram um dos meios de compreender de forma mais profunda, como a sociedade via, aceitava ou negligenciava seu líder.

Palavras-chave: História; Cartas; Adolf Hitler; Partido Nazista; Popularidade.

\footnotetext{
${ }^{1}$ História/Universidade do Vale do Paraíba/FEA, Brasil. E-mail: pedrocvslima@hotmail.com.

2 História/ Universidade do Vale do Paraíba/FEA, Brasil. E-mail: acissej.sotnas@hotmail.com.

3 História/ Universidade do Vale do Paraíba/FEA, Brasil. E-mail: felipe1997923@gmail.com.

${ }^{4}$ História/ Universidade do Vale do Paraíba/FEA, Brasil. E-mail: vzanetti@univap.br.
} 